\title{
Purpose, Quality, and Value in Critical Realist Research within Nurse Education
}

\author{
Phil Coleman ${ }^{1}$ \\ Staff Tutor/Senior Lecturer, School of Health, Wellbeing \& Social Care \\ Faculty of Wellbeing, Education \& Language Studies \\ The Open University, United Kingdom \\ Corresponding Author: Phil Coleman (phil.coleman@open.ac.uk)
}

\begin{abstract}
Background: There have been a wide range of practice fields in nursing research, including education; however, the quality of research in these disciplines has often failed to provide a sufficiently robust foundation.

Purpose: This paper explores the purpose of educational research, how quality can be assured in such research and how the value of a research study in nurse education can be determined; focusing predominantly on arguments associated with the use of qualitative, and to a lesser extent, mixed methods research.

Methods: A Critical Realist review drawing upon relevant literature from the fields of nursing, education, and healthcare was undertaken to examine issues of purpose, quality, and value in such research.

Results: A wide range of criteria were identified to evaluate the purpose, quality, and value of Critical Realist research using qualitative and mixed methods research within nurse education.

Conclusion: The holistic, theoretically-eclectic, pragmatic, and solution-focused nature of nursing as a discipline means that Critical Realist research in nursing, and more specifically, nurse education should explicitly reflect these principles.

Keywords: Critical realist; nurse education; research

BACKGROUND

Scientific research is "a continual process of rigorous reasoning supported by a dynamic interplay among methods, theories, and findings" (National Research Council Committee on Scientific Principles for Education Research [NRCCSPER], 2002, p.2). Education and healthcare both involve "complex human interactions that can rarely be studied or explained in simple terms" (Anderson, 2010, p.1) and there has been considerable debate in these fields regarding the most appropriate research methods to best inform policy and practice (Beck, 2009; Gorard \& Cook 2007; Mays \& Pope, 2000; Onwuegbuzie \& Leech, 2005). While quantitative research captures more precise measurable outcomes, qualitative studies may facilitate understanding of the nature of problems and contextualize them; hence these different approaches to scientific investigation are increasingly regarded as complementary (Anderson, 2010; Sutton \& Austin, 2015).
\end{abstract}


During the twentieth century, recognition of qualitative research as a legitimate approach to systematic inquiry was slow to develop (Anderson \& Herr, 1999; Bogdan \& Knopp-Bilken, 2010) but in the new millennium such work is enjoying unprecedented popularity and is commonplace in both healthcare (Mays \& Pope 2000, Barbour 2001) and education (Cooley, 2013; Torrance, 2012) whilst Positivist research employing quantitative methods has been the focus of growing and sustained criticism within the social sciences (Kinsella, 2007; Patomaki \& Wight, 2000). It is perhaps unsurprising that there has also been a concurrent "groundswell of conceptual interest in mixed methods approaches to social inquiry" (Greene, 2008, p.7). Research based on the philosophy of Critical Realism, sometimes termed transcendental or complex realism (Clark, 2008), which regards the identification of mechanisms and processes underlying observed phenomena as the prime function of research (Oltmann \& Boughey, 2012; Wand, White, \& Patching, 2010) has also gained "prominence as an alternative research framework particularly in the social sciences but also in nursing" (Terry, 2013, p.62).

Nursing research is undertaken in a wide range of practice fields including clinical care, health systems, leadership and education (American Association of Colleges of Nursing [AACN], 2006, Swedish Society of Nursing [SSN], 2016) and all nurses are now expected to demonstrate that their practice is based upon empirical evidence (Beck, 2009). Although establishing what works may be crucial in developing appropriate policy and practice within healthcare and education (Gorard \& Cook, 2007, Leach \& Tucker, 2018), the quality of research in these disciplines has often been described as poor; failing to provide a sufficiently robust foundation on which to make informed decisions (Feuer, Towne, \& Shavelson, 2002; Luttrell, 2010; Smith, 2014; Smith et al., 2008; Van Cleave, 2012).

\section{PURPOSE}

This paper explores the purpose of educational research and how the quality and value of research studies in nurse education can be determined. It examines these issues from the philosophical perspective of Critical Realism, focusing predominantly on arguments associated with the use of qualitative and, to a lesser extent, mixed methods research.

\section{METHODS}

A Critical Realist approach underpinned this literature review. Whereas a systematic review collates the number of 'quality' studies that support or challenge a hypothesis (Clegg 2005), a Critical Realist review seeks to present evidence in the form of ideas, theories and logic into a coherent argument (Edgley, Stickley, Timmons, \& Meal, 2016). Academic Search Complete, BioMed Central, CINAHL with Full Text, the Directory of Open Access Journals, Emerald Premier, Google, Google Scholar, Internurse, OvidSP Journals, PubMed, Sage Journals Online, Taylor \& Francis Journals Online, university library texts, several online United Kingdom broad-sheet newspapers and healthcare websites were used as the resources of this review.

Key search terms were derived from professional discussions with academic colleagues involved in the delivery of both pre-registration nursing program and more general education courses. As indicated in Figure 1, the literature search ultimately generated 73 distinct items of relevance to the review; i.e., pertinent to the principles of qualitative 
and mixed methods research underpinned by a Critical Realist philosophy and/or related to research practice within education and nursing. Specific assertions within the paper are driven by the extent of the literature discovered to support them.

Rather than demonstrating objectivity, Critical Realist researchers are expected to lead the reader towards a position through the logic of their evidence-based argument and thereby facilitate the third-party evaluation of their assertions (Edgley et al., 2016). Congruent with this philosophical approach, this paper does not, therefore, explicitly distinguish its results from points of discussion and adopting such an approach is designed to stimulate further debate on the topics addressed.

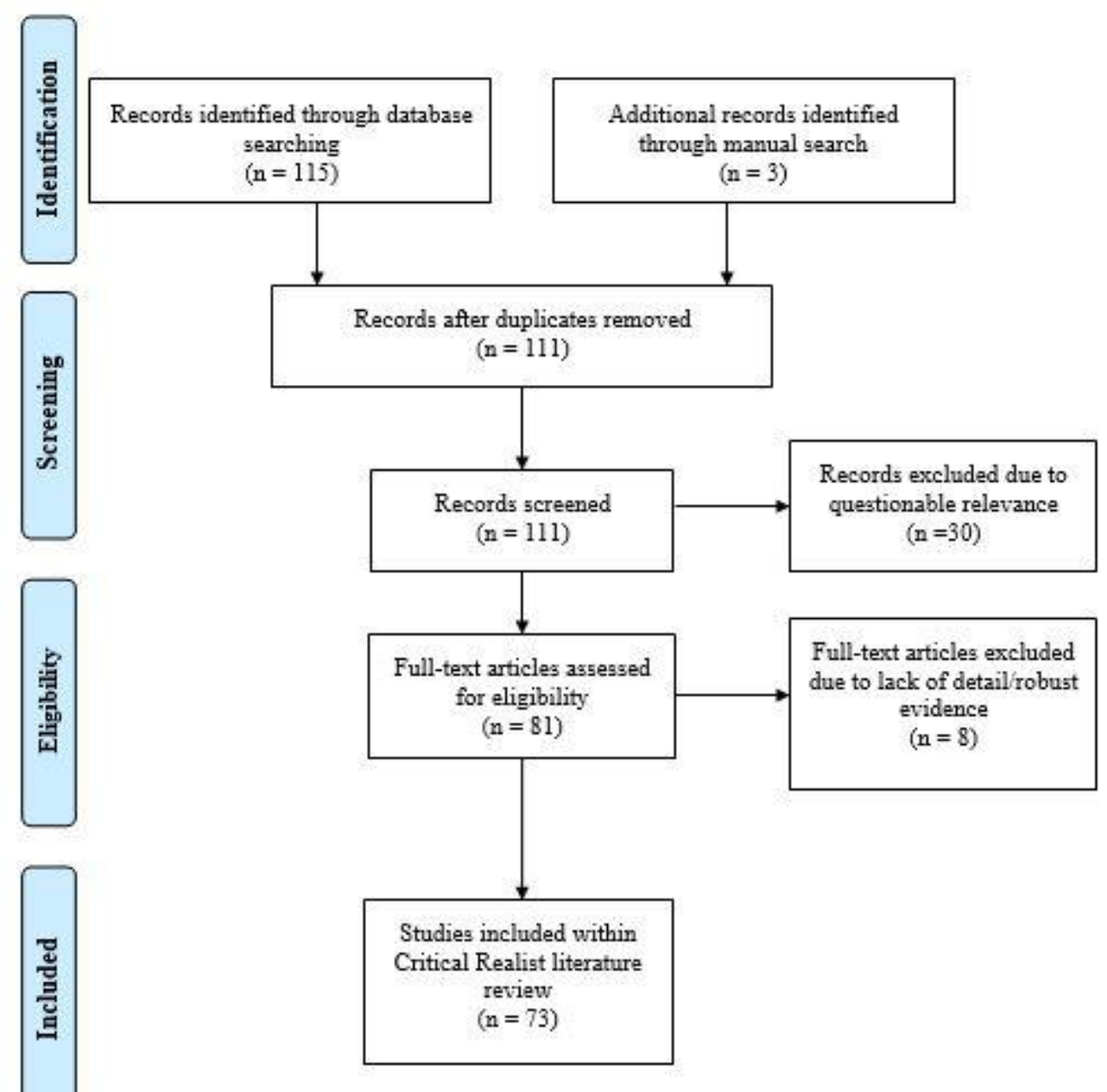

Figure 1. The selection of articles included in the review

\section{RESULTS AND DISCUSSION}

\section{The purpose of educational research in nursing}

Gorard and Cook (2007, p.318) describe education as "a very applied field of research" and, like many other disciplines, nursing has a skills component which is a critical part of its educational process (Rennie, 2009). Several writers, therefore, argue that 
educational research should be educative or have a direct relevance to, and impact on, educational policy and practice (Hammersley, 2003). For example, Carr (2007, p.271) states that such research should generate "knowledge that will have a significant and worthwhile effect on the decisions and judgments of educational policymakers and practitioners"; whilst the AACN (2006) suggest that nursing education research should, amongst other goals, develop and test educational processes, identify new ways to incorporate technology to enhance learning and discover and promote more effective approaches to lifelong learning. Pring (2000, p.247), however, claims that educational research has been "subject to damaging criticism from both outside and within the research community" precisely because of its failure to explicitly assist professional practice, generate transferable and generalizable findings, make research accessible to the broader profession and answer the questions which government and policy-makers pose.

In nursing, the assertion that research should be educative is perhaps best illustrated by the view that nurse researchers should be instrumental in addressing the theory-practice gap. This term refers to the longstanding and commonly held belief within the discipline that there is a continuing disjunct between best practice, as identified by nursing research, and the actual practice of many nurses, which is founded instead on a set of shared common-sense understandings (Brossett-Garner, 2014; Fealy, 1997). Recognition that "research depends on its relationships with practice" (NRCCSPER, 2002, p.5) has therefore led to calls for increased efforts within nursing to develop strategies to bridge the theory-practice gap (Moreno Casbas, 1999), strengthen relationships between education and service providers (National Nursing Research Unit [NNRU], 2012), "bring research and nursing practice closer together" (Leach \& Tucker, 2018 , p.171) and, by doing so, ensure research is embedded in the content of nursing education program (SSN, 2016) and makes a meaningful contribution to safe, effective and efficient care provision (CareSearch, 2011; Royal College of Nursing [RCN], 2009).

Within both healthcare (Fisher \& Freshwater, 2015; Stiles, 1993) and education (Watson \& Watson, 2011; Woolner, Hall, \& Wall, 2007) there has been an enduring view that a critical purpose of research is its potential to be emancipatory; i.e. designed to promote social justice, give a voice to those whose experiences and views may not otherwise be heard and facilitate positive social change for stakeholders. Indeed, Woolner et al. (2010, p.3) suggest that if "students' attitudes and opinions are proposed as a vital link between the environment and their learning experience, then it seems important to consider them", whilst Groundwater-Smith and Mockler (2007) assert that the need for educational research to serve the interests of practitioners and other stakeholders is arguably of greater importance than responding to government priorities.

The concept of practitioner research in education, "with its focus upon local inquiries designed to address and ameliorate local problems" (Groundwater-Smith \& Mockler, 2007, p.200), also appears to support the view that educational research should be pragmatic and solution-focused. The "split between academics in education and practitioners" (Anderson \& Herr, 1999, p.13) has traditionally led practitioners to be regarded as responsible only for implementing the work of researchers (Groundwater- 
Smith \& Mockler, 2007). Moreover, although "educational research relies critically on relationships between researchers and those engaged in professional practice" (Feuer et al., 2002, p.7), professional researchers in education may be too distant from the practice setting and lack the direct responsibility for practice that might otherwise encourage them to adopt a more grounded approach to their investigations (Kinsella, 2007; Stenhouse, 1981).

If the purpose of educational research is to provide solutions to educational problems and enhance the teaching and learning experience as some writers argue, then it may need to become more relevant to the needs of practitioners and policymakers, more coherent, unified and homogenous (Carr, 2007; Fealy, 1997) and actively involve educators in a more meaningful way (Anderson \& Herr, 1999; Feuer et al., 2002). Indeed, it is claimed that a continued failure to achieve these goals will mean educational research remains a fractured, fragmented, inaccessible, and mostly irrelevant activity (Carr, 2007; Pring, 2000).

Nevertheless, the belief that the fundamental purpose of educational research is to be educative is not one held by all members of the academic community within this discipline. Stenhouse (1981, p.113) suggests that research in education should simply aim to be "contributory to the educational enterprise", while Mays and Pope (2000, p.52) maintain that research is of value in all instances "when it either adds to knowledge or increases the confidence with which existing knowledge is regarded". Groundwater-Smith and Mockler (2007, p.201) offer some support to this view; suggesting that educational research should be concerned as much with the factors that may generate educational problems as their solution.

Carr (2007, p.273) claims "the sad truth is that educational research now embraces many traditions, paradigms, theoretical perspectives, methodological frameworks, and academic disciplines" and condemns its lack of coherence and homogeneity. Others, however, celebrate the value of a multidisciplinary approach to such investigation, believing that it has greater potential to be creative, innovative and less restricted by a narrow set of rules, values and customary practices (Cody, 1996; Groundwater-Smith \& Mockler, 2007; Mulholland, 1997). Hammersley (2003, p.13) goes further, asserting that research in education "should always aim at being informative rather than educative" and that any activity designed to improve educational action should be regarded as the work of the educationist, not the researcher. Moreover, he suggests that that empirical evidence cannot be the sole basis for changes in educational policy and practice and that researchers do not have any distinctive authority to make value judgments on such matters.

Qualitative research seeks to understand human experience within the social world, is especially useful in complex or poorly understood fields of investigation (Fossey, Harvey, McDermott, \& Davidson, 2002; Thorn, 2000) and is therefore valued by policymakers for the cultural and organizational insights it can provide (Torrance, 2012). Gorard and Cook (2007, p.317), however, claim that strict adherence to a qualitative or quantitative research approach may "write off entire fields of endeavour" and so there is also an argument to support the use of both methods within educational 
inquiry (Pring, 2000). Indeed, Greene (2008) suggests that mixed methods research may be especially valuable in highly practical disciplines where traditional theory provides only a limited credible explanation of phenomena.

Critical Realist studies seek to establish underlying structures, powers, and mechanisms that may affect behaviour and experience (Clegg, 2005; O'Mahoney \& Vincent, 2014) and by so doing "develop deeper levels of explanation and understanding" (McEvoy \& Richards, 2006, p.69). The use of both qualitative and quantitative methods is considered appropriate and more likely to generate a better understanding of the subject being investigated (Miller \& Tsang, 2010); thereby helping to establish the most probable explanation for the data acquired (Clegg, 2001). Ultimately, such research should strive to implement positive change (Collier, 1994) and arrive at "reasoned conclusions about how organizations and practices should be" (Edgley et al., 2016, p.326). One might, therefore, argue that the purpose of educational research underpinned by Critical Realism within the field of nursing should ultimately be to improve teaching and learning provision for the benefit of all its stakeholders.

\section{Research quality in nurse education}

The poor quality of many educational studies, especially their lack of epistemic rigor and practical relevance (Carr, 2007), has led to the claim that many findings cannot be implemented safely (Gorard \& Cook, 2007). Arguably, high-quality research demonstrates "a systematic and rigorous approach to the design and implementation of the study, the collection and analysis of data, and the interpretation and reporting of findings" (Fossey et al., 2002, p.720). Historically, research has been ranked according to the type of evidence it generates; quantitative randomized controlled trials [RCTs] being accorded the highest status and wholly qualitative studies the lowest position in this hierarchy (Evans \& Benfield, 2001; Hewitt 2009; Sellman, 2010).

Nevertheless, the most crucial consideration in determining quality may instead be whether the design is fit for purpose (Arksey \& Knight, 1999). Different research questions inevitably require different approaches (Gorard \& Cook, 2007), and Feuer et al., (2002, p.8) suggest "no method is good, bad, scientific, or unscientific in itself: rather, it is the appropriate application of the method to a particular problem that enables judgments about scientific quality". A researcher must clearly articulate and justify the philosophical orientation of their study (Scott, 2007; Schiller, 2016), since doing so allows others to assess the appropriateness of the methodology selected to address the research question (Samsi, 2012; Wilson \& McCormack, 2006) and consider how the researcher's perspective might affect interpretation of their findings (BeharHorenstein \& Feng, 2015).

Quality is judged differently in quantitative and qualitative research (Beck, 2009; Mays \& Pope, 2000). Issues such as reliability and validity, originally deemed "irrelevant to the qualitative enterprise" (Thorn, 2000, p.69), are now regarded as applicable to both quantitative and qualitative studies (Anderson, 2010). In qualitative research, reliability refers to the trustworthiness of data, while validity addresses the trustworthiness of the researcher's interpretations and generalizations (Mischler, 1990; Stiles, 1993). 
Examining the reliability and validity of the data and the way it is interpreted enables the objectivity and credibility of a study to be assessed (Anderson, 2010).

No single criterion is an adequate test of validity and reliability within qualitative research (Stiles, 1993), so multiple techniques are employed to determine these aspects of quality. Credibility "refers to the believability of the data and the confidence one has in the truth of the findings" (Beck, 2009, p.544) and is enhanced by asking participants to validate data and analyses; termed respondent validation (Barbour, 2001). Such validation, however, is not unproblematic since participants may, on reflection, decide to revise data to project a more socially desirable image of themselves (Burnard, Gill, Stewart, Teasure, \& Chadwick, 2008), have a limited and biased view of the findings (Torrance, 2012) and fail to appreciate the broader issues identified within the study due to their narrow role within the research process (Mays \& Pope, 2000).

Reliability and validity within qualitative research may also be enhanced by examination and explanation of findings that contradict, or are inconsistent with, most results from the study; known as deviant case analysis (Arksey \& Knight, 1999; Samsi, 2012). Other techniques include constant comparison where one piece of data is not considered on its own but compared with all previous data, thereby promoting a holistic approach to analysis (Anderson, 2010), and fair dealing where a research design incorporates various stakeholder group perspectives to ensure no single group is represented as providing the definitive 'truth' associated with the phenomena under investigation (Mays \& Pope, 2000). Moreover, confirmability, or assessment of the study data by two or more people to achieve more consistent and objective agreement regarding its meaning (Beck, 2009; Groundwater-Smith et al., 2002), may be employed. Barbour (2001) claims that the real value of this approach, however, is less to do with the extent to which different researchers agree on an interpretation of the data, but the nature of any disagreements and how these lead to coding revisions.

Arguably one of the essential tools to promote rigor in qualitative research is triangulation. This term refers to the use of two or more data sources or collection methods to establish patterns of convergence or corroborate overall interpretations within a study (Anderson, 2010; Stiles, 1993). Mixed methods research facilitates triangulation (Samsi, 2012) but others question the implicit assumption that any weakness in one method will necessarily be compensated by the strengths of another (Mays \& Pope, 2002) and stress that different methods merely provide parallel datasets; each of which only offers a partial view of the studied phenomena (Barbour, 2001).

Critical reflexivity or displaying sensitivity to how "the researcher and the research process have shaped the collected data, including the role of prior assumptions and experience" (Mays \& Pope, 2000, p.51), is also a critical component in qualitative research (Alvesson, 2003; Mellor, 2001). It enables researchers to demonstrate that cultural affiliations and lived experiences have not hindered their reporting or interpretation of the research (Behar-Horenstein \& Feng, 2015) or at least make explicit the potential effect of these factors on the study (Sutton \& Austin, 2015). 
Education is influenced by research from many disciplines (NRCCSPER, 2002). Within nurse education, quality research may need to respect the academic and philosophical foundations of nursing; which is based on theoretical eclecticism and holism (Brossett Garner, 2014; Fealy, 1997; Mulholland, 1997; Wilshaw, 1997). Indeed, Cody (1996) suggests that, in addition to its own, nursing draws upon the theoretical and research knowledge base of eleven disciplines and that such diversity may help promote innovation; hence the AACN (2006, p.3) claims that nurses are uniquely qualified to lead and participate in interdisciplinary research teams.

Whatever research method is employed, to be of good quality, a study must be guided by clear ethical principles (Groundwater-Smith \& Mockler, 2007; Sutton \& Austin, 2015). Nursing, in common with many other disciplines, requires researchers to secure approval for their work from the relevant research ethics committee and ensure they address the issues of informed consent, right to withdraw, potential benefits and harms, confidentiality and data protection before commencing a study (Nursing \& Midwifery Council [NMC], 2018; RCN, 2009). Anderson and Herr (1999) claim that practitioner research is never an apolitical enterprise, and Stiles (1993), therefore warns that interpretation of participant experiences may risk becoming a political and scientific act. Researchers may, therefore, need to carefully consider how both the interests of research participants and the aims of their study can be met to appropriately address "issues of power and structural inequalities in the research setting" (Arksey \& Knight, 1999, p.14).

Ethical research practice, however, is not limited to ensuring participant wellbeing. Gorard and Cook (2007, p.315) argue that, to be wholly ethical, any research which is publicly-funded must also be of a satisfactory quality, since the public "have the right to expect that the research is conducted in such a way that it is possible for the researcher to test and answer the questions asked". Moreover, Critical Realism considers that individuals have the potential for emancipation (Clark, 2008) and facilitating such emancipation is regarded as a central scientific concern (Madill, 2008); hence research founded on this philosophy should also seek to empower and promote positive change for its stakeholders.

\section{The value of a research study within nurse education}

The NRCCSPER (2002, p.3-6) propose six principles which should underlie scientific inquiry within education and arguably provide useful measures of whether such research has value; namely that a study should "pose significant questions that can be investigated empirically", "link research to relevant theory", "use methods that permit direct investigation of the question", "provide a coherent and explicit chain of reasoning", "replicate and generalize across studies" and "disclose research to encourage professional scrutiny and critique". To this list, Carr (2007) adds practical relevance, which Arksey and Knight (1999, p.14) describe as the providing "a clear answer to the so what question". Stenhouse (1981) agrees, suggesting studies generating accurate predictions on the context of action and the outcomes of identified acts are the most explicit applications of science to practice. Indeed, Gorard and Cook (2007) believe that studies able to identify what works should be afforded special status within educational research. 
In nurse education, it is argued that effective research must be undertaken by researchers with comprehensive subject knowledge of their field of inquiry (Knowles \& Gray, 2011), should clearly demonstrate what mechanisms best promote professional socialization and identify the educational approaches that most effectively prepare nurses for their varied practice roles (AACN, 2006). It should also generate findings capable of integration within nurse education programs (SSN, 2016). Since attrition rates for pre-registration nursing courses in the United Kingdom are as high as $25 \%$ in some universities (Willis, 2015) and applications to nursing degree programs in England have reduced by 32\% since bursaries ended in 2016 (Savage, 2019) studies capable of providing practical solutions to these challenges based on compelling empirical evidence must be regarded as especially valuable.

Within qualitative research, a study considered to have value has been described as one that should be academically robust, clear, readable, feels believable, leads to new understandings, strikes a chord, seems complete, honest and makes recommendations practitioners feel able to at least partially implement (Mellor, 2001; Sutton \& Austin, 2015). It is also one that can "transform raw data into new knowledge" (Thorn, 2000, p.68) or increase the confidence assigned to existing knowledge (Mays \& Pope, 2000), generate understanding which can co-exist with our established beliefs and explain the same phenomena as rival interpretations but also indicate "how the rivals exist and why they are mistaken" (Stiles 1993, p.608). Although qualitative research is often condemned as small scale, biased, anecdotal and lacking rigor (Anderson 2010), Gorard \& Cook (2007, p.312) assert that "valid causal knowledge has often come from nonexperimental and nonquantitative sources". Stiles (1993, p.596) also defends such research, arguing that "describing an experience in words abstracts it and simplifies it, but not nearly so much as does project it onto any manageable number of quantitative dimensions".

Critical Realism was primarily developed in the social and health sciences, and research founded on this philosophy is expected to provide a rigorous description, adequate conceptualization, and convincing explanation (Clark, 2008). Supporting the view that "no single method is likely to afford a comprehensive account of the phenomenon under investigation" (Torrance, 2012, p,112), such studies commonly employ mixed methods to reduce bias and create more detailed evidence of structures, mechanisms and processes (Miller \& Tsang, 2010) and in so doing offer more compelling and persuasive accounts and explanations; an approach referred to as critical multiplism (Bisman, 2010).

\section{CONCLUSION}

It is evident that there are diverse opinions on the purpose of educational research, how research quality should be determined, and what demonstrates that a research study in nurse education has value. These opinions are shaped by, amongst other factors, the priorities researchers, educators. Policymakers and other stakeholders assign to educational research, the ontological and epistemological assumptions of such individuals, the specific professional, historical and cultural context in which research and practice take place, whether this activity is regarded as one that should be educative 
or just informative and whether educational research should be undertaken only by those working in education or be open to multidisciplinary inquiry.

Research within nurse education founded on Critical Realism inevitably tends to use mixed methods, has pragmatic, solution-focused and emancipatory goals and is shaped by the principles of theoretical eclecticism and holism on which nursing has been established. Arguably, all research within nurse education based on these philosophical principles should, as minimum requirements, strengthen the knowledge base within this field and thereby have a positive effect on the student learning experience and, ultimately, the quality of nursing care.

\section{REFERENCES}

Alvesson, M. (2003). Beyond neopositivists, romantics and localists: A reflexive approach to interviews in organisational research. Academy of Management Review, 28(1), 13-33.

American Association of Colleges of Nursing [AACN]. (2006). AACN position statement on nursing research. Aliso Viejo: American Association of Colleges of Nursing.

Anderson, C. (2010). Presenting and evaluating qualitative research. American Journal of Pharmaceutical Education, 74(8) Article 141,1-7.

Anderson, G. \& Herr, K. (1999). The new paradigm wars: Is there room for rigorous practitioner knowledge in schools and universities?. Educational Researcher, 28(5), 12-21.

Arksey, H. \& Knight, P. (1999). Interviewing for social scientists: An introductory resource with examples. London: Sage.

Barbour, R. (2001) Checklists for improving rigour in qualitative research: A case of the tail wagging the dog?. British Medical Journal, 322(7294), 1115-1117.

Beck, C. T. (2009). Critiquing Qualitative Research. Archives of Research in Nursing Journal, 90(4), 543-554.

Behar-Horenstein, L. \& Feng, X. (2015). Emancipatory research: A synthesis of quantitative evidence. IOSR Journal of Research \& Method in Education, 5(3), 46-56.

Bisman, J. (2010) Postpositivism and accounting research: A (personal) primer on critical realism. Australasian Accounting Business and Finance Journal, 4(4), 325.

Bogdan, R. \& Knopp Biklen, S. (2010). Foundations of qualitative research in education. In Luttrell, W. (ed). Qualitative Educational Research. Abingdon: Routledge.

Brossett-Garner, D. (2014). Theories from the behavioral sciences. In McEwan M. \& Wills, E. Theoretical basis for nursing. 4th Ed. Philadelphia: Wolters Kluwer.

Burnard, P., Gill, P., Stewart, K., Teasure, E. \& Chadwick, B. (2008). Analysing and presenting qualitative data. British Dental Journal, 204(8), 429-432.

CareSearch. (2011). Evidence-based practice: Nurses as researchers. Retrieved from: https://www.caresearch.com.au/caresearch/Portals/0/Documents/PROFESSIONA L-GROUPS/Nurses\%20Hub/NH_EBP_Nurses-as-Researchers_July_2011.pdf.

Carr, W. (2007). Educational research as a practical science. Journal of Research \& Method in Education, 30(3), 271-286. 
Clark, A. (2008). Critical realism. In Given, L. (ed) The Sage Encyclopedia of Qualitative Research Methods. Thousand Oaks: Sage.

Clegg, S. (2001). Is computing really for women? A critical realist approach to gender issues in computing. In Lopez, J. \& Potter, G. (eds.). After postmodernism. An introduction to critical realism. London: The Athlone Press.

Clegg, S. (2005). Evidence-based practice in educational research: A critical realist critique of systematic review. British Journal of Sociology of Education, 26(3), 415-428.

Cody, W. (1996). Drowning in eclecticism. Nursing Science Quarterly, 9(3), 86-88.

Collier, A. (1994). Critical realism. An introduction to Roy Bhaskar's philosophy. Verso: London.

Cooley, A. (2013). Qualitative research in education: The origins, debates, and politics of creating knowledge. Educational Studies, 49(3), 247-262.

Edgley, A., Stickley, T., Timmons, S. \& Meal, A. (2016). Critical realist review: Exploring the real, beyond the empirical. Journal of Further and Higher Education, 40(3), 316-330.

Evans, J. \& Benfield, P. (2001). Systematic reviews of educational research: Does the medical model fit?. British Educational Research Journal, 27(5), 527-541.

Fealy, G. (1997). The theory-practice relationship in nursing: An exploration of contemporary discourse. Journal of Advanced Nursing, 25, 1061-1069.

Feuer, M., Towne, L. \& Shavelson, R. (2002). Scientific culture and educational research. Educational Researcher, 31(8), 4-14.

Fisher, P. \& Freshwater, D. (2015). An emancipatory approach to practice and qualitative inquiry in mental health: Finding 'voice' in Charles Taylor's ethics of identity. Ethics and Social Welfare, 9(1), 2-17.

Fossey, E., Harvey, C., McDermott, F. \& Davidson, L. (2002). Understanding and evaluating qualitative research. Australian and New Zealand Journal of Psychiatry, 36(6), 717-732.

Gorard, S. \& Cook, S. (2007) Where does good evidence come from?. International Journal of Research \& Method in Education, 30(3), 307-323.

Greene, J. (2008). Is mixed methods social inquiry a distinctive methodology?. Journal of Mixed Methods Research, 2(1), 7-22.

Groundwater-Smith, S. \& Mockler, N. (2007). Ethics in practitioner research: An issue of quality. Research Papers in Education, 22(2), 199-211.

Hammersley, M. (2003). Can and should educational research be educative?. Oxford Review of Education, 29(1), 3-25.

Hewitt, J. (2009). Redressing the balance in mental health nursing education: Arguments for a values-based approach. International Journal of Mental Health Nursing, 18(5), 368-79.

Kinsella, E. (2007). Technical rationality in Schön's reflective practice: Dichotomous or non-dualistic epistemological position. Nursing Philosophy, 8(2), 102-113.

Knowles, J. \& Gray, M. (2011). The experience of critiquing published research: Learning from the student and researcher perspective. Nurse Education in Practice, 11(6), 390-394.

Leach, M. \& Tucker, B. (2018). Current understandings of the research-practice gap in nursing: A mixed-methods study. Collegian, 25(2), 171-179. 
Luttrell, W. (2010). Introduction. The promise of qualitative research in education. In Luttrell, W. (ed). Qualitative Educational Research. Abingdon: Routledge.

Madill, A. (2008). Realism and critical approaches. In Given, L. (ed). The Sage Encyclopedia of Qualitative Research Methods. Thousand Oaks: Sage.

Mays, N. \& Pope, C. (2000). Assessing quality in qualitative research. British Medical Journal, 320, 50-52.

McEvoy, P., \& Richards, D. (2006). A critical realist rationale for using a combination of quantitative and qualitative methods. Journal of Research in Nursing, 11(1), 66-78.

Mellor, N. (2001). Messy method: The unfolding story. Educational Action Research, 9(3), 465-484.

Miller, K. \& Tsang E. (2010) Testing management theories: Critical realist philosophy and research methods. Strategic Management Journal, 32(2), 139-158.

Mischler, E. (1990). Validation in inquiry-guided research: The role of exemplars in narrative studies. Harvard Educational Review, 60(4), 415-442.

Moreno Casbas, T. (1999). Building a European nursing research strategy. Madrid: Instituto de Salud Carlos III.

Mulholland, J. (1997). Assimilating sociology: Critical reflections on the 'Sociology in nursing' debate. Journal of Advanced Nursing, 25(4), 844-852.

National Nursing Research Unit [NNRU]. (2012). Policy+Review. Kings College: London.

National Research Council Committee on Scientific Principles for Education Research [NRCCSPER]. (2002). Scientific research in education. Washington: National Research Council.

Nursing \& Midwifery Council [NMC]. (2018). The code. Professional standards of practice and behaviour for nurses, midwives and nursing associates. London: Nursing and Midwifery Council.

Oltmann, C. \& Boughey, C. (2012). Using critical realism as a framework in pharmacy education and social pharmacy research. Research in Social and Administrative Pharmacy, 8(4), 333-337.

O'Mahoney, J. \& Vincent, S. (2014). Critical Realism as an empirical project: A beginner's guide. In Edwards, P., O'Mahoney, J. \& Vincent, S. (eds). Studying organizations using critical realism. A practical guide. Oxford: Oxford University Press.

Onwuegbuzie, A. \& Leech, N. (2005). Taking the "Q" out of research: Teaching research methodology courses without the divide between quantitative and qualitative paradigms. Quality \& Quantity, 39(3), 267-295.

Patomaki, H. \& Wight, C. (2000). After postpositivism? The promises of critical realism. International Studies Quarterly, 44(2), 213-237.

Pring, R. (2000). The 'false dualism' of education research. Journal of Philosophy of Education, 14(2), 247-260.

Rennie, I. (2009). Exploring approaches to clinical skills development in nursing education. Nursing Times, 106(3), 20-22.

Royal College of Nursing [RCN]. (2009). Research ethics. RCN guidance for nurses. London: Royal College of Nursing.

Samsi, K. (2012). Critical appraisal of qualitative research. London King's College. Retrieved from https://www.kcl.ac.uk/scwru/pubs/2012/conf/samsi26jul12.pdf. 
Savage, M. (2019). NHS England loses 6,000 mental health nurses in 10 years. The Guardian, 19/5/19. Retrieved from: https://www.theguardian.com/society/2019/ may/19/mental-health-nursing-numbers-6000-fall-nhs-england.

Schiller, C. (2016). Critical realism in nursing: An emerging approach. Nursing Philosophy, 17(2), 88-102.

Scott, D. (2007) Resolving the quantitative-qualitative dilemma: A critical realist approach. International Journal of Research \& Method in Education, 30(1), 3-17.

Sellman, D. (2010). 'Values and Adult General Nursing'. In Pattison, S., Hannigan, B., Pill, R. \& Thomas, H. (eds). Emerging values in health care: The challenge for professionals. London: Jessica Kingsley Publishers.

Smith, R. (2014). Medical research-still a scandal. The BMJ opinion. Retrieved from https://blogs.bmj.com/bmj/2014/01/31/richard-smith-medical-research-still-ascandal/

Smith, B. A, Lee, H.-J., Lee, J. H., Choi, M., Jones, D., Bausell, R. B., .. \& Broome, M. (2008). Quality of reporting randomized controlled trials (RCTS) in the nursing literature: Application of the consolidated standards of reporting trials (CONSORT). Nursing Outlook, 56(1), 31-37.

Stenhouse, L. (1981). What counts as research?. British Journal of Educational Studies, 29(2), 103-114.

Stiles, W. (1993). Quality control in quality research. Clinical Psychology Review, 13(6), 593-618.

Sutton, J. \& Austin, Z. (2015). Qualitative research: Data collection, analysis, and management. Canadian Journal of Hospital Pharmacy, 68(3), 226-231.

Swedish Society of Nursing [SSN]. (2016). Nursing-research and the future. A strategy for nursing research. Stockholm:S wedish Society of Nursing.

Terry, K. (2013) The competency landscape: A critical realist exploration of the ways nurses understand and utilise competency standards (Unpublished Doctoral thesis). University of Tasmania.

Thorn, S. (2000). Data analysis in qualitative research. Evidence-Based Nursing Notebook, 3, 68-70.

Torrance, H. (2012). Triangulation, respondent validation and democratic participation in mixed methods research. Journal of Mixed Methods Research, 6(2), 111-123.

Van Cleave, J. (2012). Scientifically based research in education as a regime of truth: An analysis using Foucault's genealogy and governmentality (Doctoral thesis). University of Georgia.

Wand, T., White, K. \& Patching, J. (2010). Applying a realist(ic) framework to the evaluation of a new model of emergency department-based mental health nursing practice. Nursing Inquiry, 17(3), 231-239.

Watson, S. \& Watson, W. (2011). Critical, emancipatory, and pluralistic research for education: A review of critical systems theory. Journal of Thought, 46(3-4), 6377.

Willis, L. (2015). Raising the bar. Shape of caring: A review of the future education and training of registered nurses and care assistants. Leeds: Health Education England/Nursing and Midwifery Council.

Wilshaw, G. (1997). Integration of therapeutic approaches: A new direction for mental health nurses?. Journal of Advanced Nursing, 26(1),15-19. 
Wilson, V., \& McCormack, B. (2006). Critical realism as emancipatory action: The case for realistic evaluation in practice development. Nursing Philosophy, 7(1), 45-57.

Woolner, P., Clark, J., Hall, E., Tiplady, L., Thomas, U. \& Wall, K. (2010). Pictures are necessary but not sufficient: Using a range of visual methods to engage users about school design. Learning Environment Research, 13(1), 1-22.

Woolner, P., Hall, E. \& Wall, K. (2007). Getting together to improve the school environment: User consultation, participatory design and student voice. Improving Schools, 10(3), 233-248. 